\title{
Dentistry in the national news
}

\author{
Missed out on the hot topics of the month? Here we recap some of the \\ dental stories making the news this month.
}

\section{BRITISH PEOPLE 'TOO TOLERANT' OF BAD TEETH}

British people tolerate a higher rate of dental decay and staining than their American counterparts TV doctor Dr Chris van Tulleken has claimed in the Daily Telegraph. In the article Dr van Tulleken said Britain has become 'internationally renowned' for having 'really lousy' teeth. While having stains and decay is frowned upon in America and other countries, he said 'it doesn't really bother us' in the UK.

\section{STUBBED OUT ON SAND}

Smoking could be banned in parks, sports grounds, playing fields, car parks and one beach in Pembrokeshire, $B B C$ News reported.

The story reported the local council is looking at trialling a plan to ban smoking on one beach in a bid to discourage young people from taking up the habit. E-cigarettes and vaporisers would also be banned.

\section{CHILDSMILE SAVING £5M} A YEAR, SAYS SCOTLAND'S PUBLIC HEALTH MINISTER

Scotland's Childsmile to improve

children's dental health is saving almost

$£ 5$ million a year in treatment costs, the

Public Health Minister Maureen Watt

has said. Childsmile offers every child attending nursery in Scotland free daily supervised tooth brushing. In the most deprived areas, this extends into primary schools. Children are also offered free toothbrushes, toothpaste and two fluoride varnish applications per year. The number of primary one children with 'no obvious decay experience' has risen from 54 per cent in 2006 to 68 per cent in 2014. Ms Watt said the scheme has led to substantial savings in treatment costs because fewer children require extractions, fillings and general anaesthetics. The story is reported by the Scotsman.

\section{STOP 'PUSHING' SUGARY SNACKS, NHS CHIEF WARNS FOOD FIRMS \\ The Times reports on an interview with NHS Chief Executive Simon Stevens in which he suggests that the food industry has a responsibility to reduce sugar in its products. He says that fizzy drinks and sugary snacks should become socially unacceptable and hints that laws could be implemented if firms fail to cut sugar voluntarily. \\ In response to an interview Mr Stevens' gave on the Andrew Marr Show, the Times carried a brief item highlighting a response by the Food and Drink \\ Federation. They said it was wrong to target one ingredient in tackling obesity and that sugar was not a poison.} I

\section{CALL FOR LEVY ON} TOBACCO INDUSTRY TO FUND ANTI-SMOKING

\section{MEASURES}

The government should impose a new levy on tobacco companies to help pay for the harm they cause, according to a story in the Guardian. By 2035, the proportion of the population who smoke should be brought down from 18.5 per cent to just five per cent, says the group, which is led by Action on Smoking and Health (ASH), Cancer Research UK and the British Heart Foundation.

\section{BAD TEETH STOP ONE IN FOUR SMILING IN PHOTOS}

A quarter of people refuse to smile in 'selfies' and pictures - because they are worried about their teeth looking bad on social media, according to a survey by Bupa. The survey reported in the Daily Mail shows a quarter (28 per cent) refuse to smile in pictures to hide their teeth while 81 per cent of people worry about how their teeth look in photographs. Of those surveyed, 42 per cent confessed their teeth were the number one thing they would change about themselves and more than a third admitted being embarrassed about the appearance of their teeth. Sixty-three per cent said they wished their teeth were whiter and cleaner and 53 per cent of those polled said they feel pressured to have impeccable teeth because of those displayed by modern celebrities and public figures. On the subject of oral health 47 per cent of respondents admitted they don't know how to brush their teeth properly, 29 per cent don't use toothpaste, 50 per cent don't use mouthwash, 68 per cent don't use floss; and nine per cent admitted to regularly sharing a toothbrush with someone else. The results also revealed 13 per cent don't polish behind their teeth, 41 per cent don't brush their tongue and 16 per cent don't clean their gums. One in five said they regularly use chewing gum as a substitute for brushing their teeth.

\section{COSMETIC PATIENTS SHOULD GET 'COOLING-OFF' PERIOD}

$B B C$ News has reported on a story that says doctors who carry out cosmetic procedures should give patients time to think before agreeing to go ahead, according to new guidance from the GMC. Some of the main points in the new guidance say that doctors should:

- Be open and honest with patients and not trivialise the risks involved

- Give patients enough time and information before they decide whether to have a cosmetic procedure, allowing them time to "cool off"

- Ask patients to tell them how they have been affected by a cosmetic procedure, both physically and psychologically

- Not target people under 18 through their marketing and seek additional advice from professionals who treat young people

- Not make unjustifiable claims about the results they can achieve and not give away procedures as prizes. 